\title{
Waterpipe Tobacco Smoking and Associated Risk Factors among Bangladeshi University Students: An Exploratory Pilot Study
}

\author{
Md. Sabbir Ahmed ${ }^{1} \cdot$ Liton Chandra Sen ${ }^{1} \cdot$ Safayet Khan $^{2} \cdot$ Fakir Md Yunus $^{3}$. \\ Mark D. Griffiths ${ }^{4}$
}

Published online: 26 May 2020

(C) The Author(s) 2020

\begin{abstract}
Over the past two decades, there has been a global rise in the prevalence of waterpipe tobacco smoking. Waterpipe tobacco smoking involves the inhalation of heated tobacco smoke after passing through water, and it has been associated with an identified dependence effect similar to that found with cigarette smoking. Despite the popularity of waterpipe tobacco among youth (and in particular, university students) in many countries, detailed data of its usage are lacking in Bangladesh. Therefore, the present study was conducted to explore waterpipe tobacco smoking behavior and normative beliefs among university students in Bangladesh and to assess the factors associated with waterpipe tobacco use. A quantitative crosssectional survey was carried out among 340 Bangladeshi university students (64.4\% male; mean age 21.6 years). Among participants, $13.5 \%$ reported they had ever smoked tobacco from a waterpipe and $9.4 \%$ had it in past 30 days. Among past 30 -day users, $72 \%$ were categorized as having waterpipe smoking dependence $(n=$ 23). No females in the sample had ever smoked using a waterpipe. Maternal occupation, monthly expenditure, and regular smoking status were major predominant factors associated with waterpipe smoking behavior of the students. The study is of existential value given that there are no prior studies ever carried out in Bangladesh previously. Recommendations are provided based on the study's findings, particularly in relation to what action is needed from universities in Bangladesh.
\end{abstract}

Keywords Smoking · Waterpipe tobacco smoking $\cdot$ Student tobacco use $\cdot$ Bangladeshi university students · Waterpipe dependence

Mark D. Griffiths

mark.griffiths@ntu.ac.uk

Extended author information available on the last page of the article 


\section{Introduction}

Waterpipe tobacco smoking involves the inhalation of heated tobacco smoke after passing through water. Waterpipe tobacco smoking is known by many different names in various cultural settings including shisha, hookah, calyan, narghile, or hubble-bubble (Knishkowy and Amitai 2005). About $10 \mathrm{~g}$ of flavored tobacco, sometimes mixed with other substances such as honey and molasses, are placed on the head of an apparatus, and once consumed, it can be replaced with new tobacco to enable the waterpipe session to continue (Jawad et al. 2016a; Jawad et al. 2013b). As with any tobacco smoking, waterpipe smoking also exposes users to clinically harmful levels of tobacco-specific nitrosamines (Al Ali et al. 2015; Helen et al. 2014; Radwan et al. 2012), polycyclic aromatic hydrocarbons, as well as other common toxicants found in tobacco (Jacob et al. 2013; Nguyen et al. 2013; Sepetdjian et al. 2010). Therefore, waterpipe smoking is as dangerous as cigarette smoking. Relative to non-users, evidence suggests that waterpipe users are at increased risk of cardiovascular diseases (Selim et al. 2013; Sibai et al. 2014), lung cancer (Akl et al. 2010), and other respiratory conditions (Boskabady et al. 2012; Raad et al. 2011). However, a global spread in its use has been witnessed over the past 20 years (Maziak et al. 2015). The rise in waterpipe use among young population has prompted the World Health Organization to declare the behavior a growing public health concern in its 2015 advisory note (WHO 2015).

Despite the similar kind of health risks associated with waterpipe smoking as with cigarette smoking, the use of this product continues to spread among the youth and adults in the USA (Lipkus et al. 2014). Among university students in the UK, research showed that between 38 and $52 \%$ had tried waterpipes and $8-11 \%$ of the students had engaged in waterpipe smoking in the past 30 days (Jackson and Aveyard 2008; Jawad et al. 2013a). The most recent Global Youth Tobacco Survey also identified a relatively high prevalence of the past 30-day waterpipe use in Lebanon (36.9\%), the West Bank (32.7\%), and Latvia (22.7\%) (Jawad et al. 2016b). A significantly higher prevalence of waterpipe smoking was found among males than females in some Arab countries (Al Ghobain et al. 2018; Morton et al. 2014), and in Iran, men initiated waterpipe smoking at an earlier age than women (Danaei et al. 2017). Despite the popularity of waterpipe tobacco among youth worldwide, detailed data of its usage are lacking in Bangladesh.

Waterpipe smoking has been associated with an identified dependence effect similar to that found with cigarette smoking (Hammal et al. 2008). However, there is a need to identify the risk factors associated with waterpipe tobacco use and how this is integrated with changing tobacco epidemiology among young people (Jawad et al. 2016a). Different social factors also add to the potentially addictive effects of waterpipe smoking because it is commonly performed as a social activity and a key feature of it is the sharing with other users (Ali and Jawad 2017). Greater social acceptability and tolerance toward waterpipe smoking than cigarette smoking are the motivations for female students in some Arab countries to use waterpipe (Babar and Riaz 2015; Maziak et al. 2004), and some female students also feels empowered by using it (Baheiraei et al. 2015). Several socio-demographic predictors of waterpipe tobacco smoking among the university students have been identified in recent studies including being male, being older in age, frequent alcohol consumption, higher sensation-seeking behavior, and perceived peer acceptability toward waterpipe and cigarette smoking (Lee et al. 2020; Salloum et al. 2019; Sidani et al. 2019). Increasing use of waterpipe smoking is also associated with the perception of many young adults concerning its relatively less harmful effects than 
cigarette smoking (Sidani et al. 2019; Cobb et al. 2010). Other recent research into waterpipe smoking have examined such areas as toxicity (Hauser et al. 2020), waterpipe device cleaning practice and waste disposal (Kassem et al. 2020), effects on the cardiovascular system (Qasim et al. 2019), and severity of polycythemia (AlQahtany et al. 2020), although none of this research has implications for the psychological consequences or risk factors.

Waterpipe tobacco usage among students is increasing (Arrazola et al. 2015), and university students are one of the important target groups in preventing their uptake of waterpipe smoking. One possible reason for the increase in waterpipe smoking among university students is because of their normative perceptions about waterpipe smoking (Leavens et al. 2018). There are different types of normative perceptions. Descriptive and injunctive perceptions are two different types of normative perceptions which includes perceptions of a frequency of a behavior or perceptions of approval of a specific behavior (Larimer and Neighbors 2003; Neighbors et al. 2007). Theory from normative social behavior posits that individuals overestimate the influence of peer engagement in risky behaviors (Perkins 2002). These misrepresentations can lead individuals to be less concerned about their own health which results in increased engagement in risky behaviors (Baer et al. 1991; Borsari and Carey 2003) such as waterpipe smoking.

Similarly, the false consensus effect, which is another type of cognitive bias, asserts that individuals who engage in a target behavior believe that others are also engaged with similar kind of behavior at relatively similar frequencies (Ross et al. 1977). Existing research suggests that waterpipe smoking is innately social, and that peer group pressure in waterpipe smoking is an influential factor in personal waterpipe smoking (Leavens et al. 2018). Other factors such as gender differences have also shown that males are more likely to smoke waterpipes than females (Eissenberg et al. 2008; Primack et al. 2010).

Identifying the characteristics of university students susceptible to waterpipe use is critical to design targeted intervention to prevent waterpipe use. However, study concerning the predictors of waterpipe use is non-existent in Bangladesh. No previous study has ever investigated waterpipe tobacco smoking among Bangladeshi students. Therefore, the present study was conducted to explore waterpipe tobacco smoking behavior and normative beliefs among university students in Bangladesh and to assess the factors affecting waterpipe tobacco use. The present study also attempted to explore the patterns of behavior including frequency of use and dependence on waterpipe smoking.

\section{Method}

\section{Participants and Study Design}

A quantitative cross-sectional study was carried out among the students of Patuakhali Science and Technology University (Bangladesh) to explore the study objectives (outlined above). Data were collected from August to October 2019. The only inclusion criterion for the study sample was being enrolled as a full-time student at the university. A power analysis was carried out based on the population size of the university (4000 students) with a margin of error of $5 \%$, a confidence level of $95 \%$, and a $50 \%$ response distribution which showed that at least 351 participants were needed for the survey (Dean et al. 2014). Hoping to get a $90 \%$ response, a $10 \%$ non-response rate was added. The number of students asked to participate was 385 . 
Complete data were collected from 340 students (response rate 88\%). Students were selected from each of seven university faculties. The probability proportional to size (PPS) technique was used to determine the number of students to recruit in each faculty.

\section{Data Collection}

Data were collected face-to-face using a pre-tested structured questionnaire. Six volunteer research assistants with previous survey experience were recruited to collect data. Students were selected from the faculty classroom. A list of the students with their registration number was collected from the respective faculty dean office, and this list was used as a sampling frame. From the sampling frame, students were selected randomly using a lottery method. Data collectors approached the randomly selected participants and informed them about the objectives of the study and confidentiality of the data. After having signed consent form, the data were collected from the students. Each interview took approximately 20-30 min and it was held in a private setting.

\section{Measures}

Socio-Demographics Socio-demographic data were collected including age in years, gender, study program (undergraduate vs. postgraduate), field of study, parental educational and occupational status, family monthly income (in Bangladeshi Taka [BDT]), permanent residency status (rural vs. urban area), smoking status, and monthly expenditure on tobacco products.

Waterpipe Use To assess the waterpipe smoking behavior among the students, two dichotomous items were used: (i) have you ever smoked tobacco from a waterpipe (hookah, shisha, narghile), even one or two puffs? (yes/no); (ii) during the past 30 days, have you smoked tobacco from a waterpipe (hookah, shisha, narghile), even one or two puffs? (yes/no). This part of the survey was adapted from a previous study conducted among the US university students (Primack et al. 2008). Participants' perception relating to harm and addictiveness of waterpipe use was also assessed. These questions were designed by comparing the harm/addictiveness of waterpipe tobacco smoking versus that of cigarette smoking. Two separate items were asked to assess students' belief regarding harm and addictiveness of smoking tobacco from a waterpipe. One item asked "Would you say that smoking from a waterpipe is more harmful or less harmful than smoking regular cigarettes?", and students were provided with four response categories, i.e., "waterpipe is more harmful," "waterpipe is the same harm as cigarettes," "waterpipe is less harmful," and "do not know". A similar item asked "Would you say that smoking from a waterpipe is more addictive or less addictive than smoking regular cigarettes?", and responses were similarly divided into four categories. This type of structure has been commonly used in previously published studies (Primack et al. 2008; Smith-Simone et al. 2008; Tamim et al. 2003).

Waterpipe Dependence Waterpipe dependence was assessed using the Lebanon Waterpipe Dependence Scale (LWDS-11) (Salameh et al. 2008). This scale comprises 11 items consisting of four components: nicotine dependence, positive reinforcement, negative reinforcement, and psychological craving (e.g., number of times an individual was able to stop using waterpipes for more than 7 days, the number of days an individual can spend without using waterpipes). 
Responses for each question were scored $0-3$, and total score was calculated by adding all the individual scores (total score 33 ). Individuals scoring $\geq 10$ on the LWDS- 11 are classed as having a waterpipe smoking dependence based on the original study (Salameh et al. 2008). Dependency level was assessed only for those who responded "yes" to past 30 days use of waterpipes. For this present study, the Cronbach's alpha of the LWDS was very good (0.81).

\section{Ethics}

All study procedures were carried out following the guidelines of the Helsinki Declaration. Written ethical approval was obtained from the Institutional Ethical Committee of Patuakhali Science and Technology University (Ref. PSTU/IEC/2019/03). Written informed consent was obtained from the participants before each interview. Participants were informed that their participation was voluntary, and they had the right to withdraw from the study at any time. They were also assured about the confidentiality and anonymity of the data.

\section{Data Analysis}

After completion of data entry, frequency analysis was run to check the consistency of the data. If any inconsistencies were found (such as incorrect or ambiguous entries), data were rechecked with the survey questionnaire. At first, prevalence of the major variables (i.e., waterpipe tobacco use ever and past 30 days) was assessed. Prevalence of each variable for each socio-demographic variable was computed. Chi-square tests were performed to assess the associations between categorical variables and Pearson's correlation tests were performed to assess the relationship between continuous variables. Logistic regression was used to determine the association between independent and dependent variables. The tests for the main effects were considered significant at $p<0.01$ level. A binary and multiple logistic regression analysis was conducted to determine the odd ratios (ORs) and adjusted odd ratios (AORs) with 95\% confidence intervals. All statistical analyses were performed using SPSS for Windows Version 23 (IBM, Armonk, NY, USA).

\section{Results}

\section{Participants}

The socio-demographic characteristics of participants are shown in detail in Table 1. Of the 340 participants, the majority were male $64.4 \%(n=219)$. Participants were aged between 18 to 25 years (mean age $=21.6$ years; $\mathrm{SD} \pm 1.73$ ). The majority of the students were enrolled in undergraduate programs (78\%) and came from rural areas (56\%). No female was reported having ever engaged in waterpipe tobacco smoking in their life.

\section{Prevalence of Waterpipe Tobacco Smoking}

Among participants, $13.5 \%$ reported they had smoked tobacco from a waterpipe $(n=46)$ and $9.4 \%$ had smoked tobacco from a waterpipe in past 30 days $(n=32)$. Table 1 shows 
that the use of waterpipes was higher among the younger 18-21-year age group than the $22-25$-year age group (14.9\% had used waterpipes and $10.9 \%$ has used them in the past 30 days). Use of waterpipe tobacco consumption was only reported among male students.

Table 1. Characteristics of the participants by waterpipe tobacco smoking use.

\begin{tabular}{|c|c|c|c|c|c|}
\hline \multirow[t]{2}{*}{ Characteristics } & \multirow[t]{2}{*}{ Students $(\mathrm{N}=340)$} & \multicolumn{2}{|c|}{ Ever use $(n=46)$} & \multicolumn{2}{|c|}{ Past 30-day use ( $\mathrm{n}=32$ ) } \\
\hline & & n (Row\%) & $p$-value & $\mathrm{n}($ Row\%) & $p$-value \\
\hline \multicolumn{6}{|l|}{ Age (years) } \\
\hline $18-21$ & 174 & $26(14.9)$ & \multirow[t]{2}{*}{0.526} & $19(10.9)$ & \multirow[t]{2}{*}{0.358} \\
\hline $22-25$ & 166 & $20(12.0)$ & & $13(7.8)$ & \\
\hline \multicolumn{6}{|l|}{ Gender } \\
\hline Male & 219 & $46(21.0)$ & \multirow[t]{2}{*}{$<0.001$} & $32(14.6)$ & \multirow[t]{2}{*}{$<0.001$} \\
\hline Female & 121 & $0(0.0)$ & & $0(0.0)$ & \\
\hline \multicolumn{6}{|l|}{ Study program } \\
\hline Undergraduate & 266 & $44(16.5)$ & \multirow[t]{2}{*}{$<0.001$} & $31(11.7)$ & \multirow[t]{2}{*}{$<0.01$} \\
\hline Graduate & 74 & $2(2.7)$ & & $1(1.4)$ & \\
\hline \multicolumn{6}{|l|}{ Study area } \\
\hline Agricultural science & 244 & $25(10.2)$ & \multirow[t]{3}{*}{$<0.05$} & $16(6.6)$ & \multirow[t]{3}{*}{$<0.01$} \\
\hline Engineering & 28 & $5(17.9)$ & & $3(10.7)$ & \\
\hline Business studies & 68 & $16(23.5)$ & & $13(19.1)$ & \\
\hline \multicolumn{6}{|l|}{ Father's occupation } \\
\hline Agriculture based & 37 & $2(5.4)$ & \multirow[t]{5}{*}{0.367} & $2(5.4)$ & \multirow[t]{5}{*}{0.628} \\
\hline Labor & 5 & $1(20.0)$ & & $0(0.0)$ & \\
\hline Business & 99 & $15(15.2)$ & & $9(9.1)$ & \\
\hline Job & 143 & $23(16.1)$ & & $17(11.9)$ & \\
\hline Others & 56 & $5(8.9)$ & & $4(7.1)$ & \\
\hline \multicolumn{6}{|l|}{ Mother's occupation } \\
\hline Housewife & 262 & $12(4.6)$ & \multirow[t]{2}{*}{$<0.001$} & $11(4.2)$ & \multirow[t]{2}{*}{$<0.001$} \\
\hline Working outside & 78 & $34(43.6)$ & & $21(26.9)$ & \\
\hline \multicolumn{6}{|l|}{ Permanent residence } \\
\hline Rural area & 190 & $13(6.8)$ & \multirow[t]{2}{*}{$<0.001$} & $9(4.7)$ & \multirow[t]{2}{*}{$<0.001$} \\
\hline Urban are & 150 & $33(22.0)$ & & $23(15.3)$ & \\
\hline Family size & & & & & \\
\hline$\leq 4$ & 162 & $22(13.6)$ & 0.979 & $17(10.5)$ & 0.579 \\
\hline$>4$ & 178 & $24(13.5)$ & & $15(8.4)$ & \\
\hline Household income (B & & & & & \\
\hline$<15 \mathrm{k}$ & 34 & $4(11.8)$ & & $3(8.8)$ & 0.835 \\
\hline $15 \mathrm{k}-30 \mathrm{k}$ & 121 & $16(13.2)$ & & $10(8.3)$ & \\
\hline$>30 \mathrm{k}$ & 185 & $26(14.1)$ & & $19(10.3)$ & \\
\hline Monthly expenditure & & & & & \\
\hline$<5 \mathrm{k}$ & 144 & $8(5.6)$ & $<0.001$ & $4(2.8)$ & $<0.001$ \\
\hline$\geq 5 \mathrm{k}$ & 196 & $38(19.4)$ & & $28(14.3)$ & \\
\hline Smoking status & & & & & \\
\hline Smoker & 84 & $41(48.8)$ & $<0.001$ & $30(35.7)$ & $<0.001$ \\
\hline Non-smoker & 256 & $5(2.0)$ & & $2(2.0)$ & \\
\hline Parental smoking & & & & & \\
\hline Yes & 92 & $21(22.8)$ & $<0.01$ & $15(16.3)$ & $<0.05$ \\
\hline No & 248 & $25(10.1)$ & & $17(6.9)$ & \\
\hline
\end{tabular}

${ }^{a}$ Chi-square test 


\section{Association between Waterpipe Smoking Behavior and Beliefs Regarding Harmfulness and Addictiveness}

Among those who had ever used waterpipes to smoke tobacco, just over one-quarter $(27.6 \%)$ of the sample believed that waterpipe tobacco smoking was less harmful than cigarette smoking, whereas $18 \%$ believed that waterpipe tobacco smoking was more harmful, and $3.7 \%$ reported they did not know (Table 2). With regard to addictiveness, $30 \%$ believed waterpipe tobacco smoking was less addictive than cigarette smoking and $25 \%$ believed waterpipe tobacco smoking was more addictive. Among the past 30 days users, $20.7 \%$ believed that waterpipe tobacco smoking was less harmful than cigarette smoking and $23 \%$ believed it was less addictive. Those who believed that tobacco smoking from a waterpipe is less harmful than cigarette smoking were more commonly waterpipe tobacco smokers. This association was statistically significant for both those that had ever used waterpipes and those that had used them in the past 30 days users $(p<0.001)$. A similar significant relationship $(p<0.001)$ was found for the addictiveness of waterpipe smoking compared with cigarette smoking (i.e., those who thought tobacco smoking from a waterpipe is less addictive than cigarette smoking were more likely to have ever used waterpipes and used them in the past 30 days) (Table 2).

\section{Association between Waterpipe Smoking and Socio-Demographic Predictors}

Table 3 shows the association between waterpipe smoking behavior and sociodemographic predictors. The regression analysis showed that there was a significant association between having ever used a waterpipe and mother's occupation. More specifically, students whose mothers were in employment had higher odds of using waterpipes than students whose mothers were housewives $(\mathrm{OR}=16.09$; 95\% CI, 7.7433.47). The odds remained high after adjusting the variables $(\mathrm{OR}=27.81 ; 95 \% \mathrm{CI}, 8.07-$ 95.83). There was also a significant association between having ever used waterpipes and cigarette smoking status. Those who were smokers were more likely to use waterpipes compared with non-smokers $(\mathrm{OR}=47.86 ; 95 \% \mathrm{CI}, 17.90-127.94)$. The odds remained high after adjusting the other variables. A similar pattern was shown among past 30-day waterpipe users.

Table 2. Association between waterpipe use and belief regarding harm and addictiveness.

\begin{tabular}{|c|c|c|c|c|c|c|}
\hline & \multicolumn{3}{|l|}{ Ever use } & \multicolumn{3}{|c|}{ Past 30-day use } \\
\hline & $\mathrm{n}(\%)$ & $X^{2}$ test value & $p$-value & n (Row\%) & $X^{2}$ test value & $p$-value \\
\hline \multicolumn{7}{|l|}{ Harm (versus cigarettes) } \\
\hline Waterpipe more harmful & $16(18.0)$ & 29.858 & $<.001$ & $12(13.5)$ & 27.838 & $<.001$ \\
\hline Waterpipe same harm & $1(3.6)$ & & & $1(3.6)$ & & \\
\hline Waterpipe less harm & $24(27.6)$ & & & $18(20.7)$ & & \\
\hline Don’t know & $5(3.7)$ & & & $1(0.7)$ & & \\
\hline \multicolumn{7}{|c|}{ Addictiveness (versus cigarettes) } \\
\hline Waterpipe more addictive & $13(25.0)$ & 51.971 & $<.001$ & $8(15.4)$ & 41.227 & $<.001$ \\
\hline Waterpipe same addictive & $0(0.0)$ & & & $0(0.0)$ & & \\
\hline Waterpipe less addictive & $30(30.0)$ & & & $23(23.0)$ & & \\
\hline Don't know & $3(1.8)$ & & & $1(0.6)$ & & \\
\hline
\end{tabular}


Table 3 Association between waterpipe smoking and socio-demographic predictors

\begin{tabular}{|c|c|c|c|c|}
\hline & \multicolumn{2}{|l|}{ Ever use } & \multicolumn{2}{|l|}{ Past 30-day use } \\
\hline & OR $(95 \% \mathrm{CI})$ & $\mathrm{AOR}^{\mathrm{a}}(95 \% \mathrm{CI})$ & OR $(95 \% \mathrm{CI})$ & $\operatorname{AOR}^{\mathrm{a}}(95 \% \mathrm{CI})$ \\
\hline \multicolumn{5}{|l|}{ Study program } \\
\hline Undergraduate & $7.13(1.68-30.16)^{* *}$ & $5.93(0.86-40.52)$ & $9.63(1.29-71.76)^{*}$ & $5.57(0.63-48.84)$ \\
\hline Graduate & $1.00^{\mathrm{b}}$ & $1.00^{\mathrm{b}}$ & $1.00^{\mathrm{b}}$ & $1.00^{\mathrm{b}}$ \\
\hline \multicolumn{5}{|l|}{ Study area } \\
\hline $\begin{array}{l}\text { Agricultural } \\
\text { science }\end{array}$ & $1.00^{\mathrm{b}}$ & $1.00^{\mathrm{b}}$ & $1.00^{\mathrm{b}}$ & $1.00^{\mathrm{b}}$ \\
\hline Engineering & $1.90(0.66-5.45)$ & $2.55(0.56-11.56)$ & $1.71(0.46-6.27)$ & $1.65(0.33-8.20)$ \\
\hline Business studies & $2.69(1.34-5.40)^{* *}$ & $3.04(0.91-10.14)$ & $3.36(1.53-7.41)^{* *}$ & $3.10(0.99-9.62)^{*}$ \\
\hline \multicolumn{5}{|c|}{ Mother's occupation } \\
\hline Housewife & $1.00^{\mathrm{b}}$ & $1.00^{\mathrm{b}}$ & $1.00^{\mathrm{b}}$ & $1.00^{\mathrm{b}}$ \\
\hline Working outside & $16.09(7.74-33.47)^{* * * *}$ & $27.81(8.07-95.83)^{* * * *}$ & $8.40(3.83-18.41)^{* * * *}$ & $5.53(1.84-16.60)^{* *}$ \\
\hline \multicolumn{5}{|c|}{ Permanent residence } \\
\hline Rural area & $1.00^{\mathrm{b}}$ & $1.00^{\mathrm{b}}$ & $1.00^{\mathrm{b}}$ & $1.00^{\mathrm{b}}$ \\
\hline Urban are & $3.84(1.94-7.60)^{* * *}$ & $1.70(0.57-5.04)$ & $3.64(1.63-8.13)^{* *}$ & $1.46(0.49-4.30)$ \\
\hline \multicolumn{5}{|c|}{ Monthly expenditure (BDT) } \\
\hline$<5 \mathrm{k}$ & $1.00^{\mathrm{b}}$ & $1.00^{\mathrm{b}}$ & $1.00^{\mathrm{b}}$ & $1.00^{\mathrm{b}}$ \\
\hline$\geq 5 \mathrm{k}$ & $4.08(1.84-9.06)^{* * *}$ & $2.02(0.58-7.03)$ & $5.83(1.99-17.03)^{* * * *}$ & $2.71(0.69-10.55)$ \\
\hline \multicolumn{5}{|l|}{ Smoking status } \\
\hline Smoker & $\begin{array}{l}47.86 \\
\quad(17.90-127.94)^{* * *}\end{array}$ & $\begin{array}{l}50.82 \\
\quad(14.31-180.47)^{* * *}\end{array}$ & $\begin{array}{l}70.55 \\
\quad(16.36-304.16)^{* * * *}\end{array}$ & $\begin{array}{l}41.36 \\
\quad(9.0-189.81)^{* * * *}\end{array}$ \\
\hline Non-smoker & $1.00^{\mathrm{b}}$ & $1.00^{\mathrm{b}}$ & $1.00^{\mathrm{b}}$ & $1.00^{\mathrm{b}}$ \\
\hline \multicolumn{5}{|l|}{ Parental smoking } \\
\hline Yes & $2.63(1.39-4.99)^{* *}$ & $2.95(1.01-8.61)^{*}$ & $2.64(1.26-5.55)^{* *}$ & $2.18(0.78-6.03)$ \\
\hline No & $1.00^{\mathrm{b}}$ & $1.00^{\mathrm{b}}$ & $1.00^{\mathrm{b}}$ & $1.00^{\mathrm{b}}$ \\
\hline
\end{tabular}

Note. $\mathrm{OR}=$ Odd Ratio, $\mathrm{AOR}=$ Adjusted Odd Ratio

a Adjusted for all variables in the table

b Reference

$* p<0.05, * * p<0.01, * * * p<0.001$

\section{Relationship between Waterpipe Dependence Score and Monthly Expenditure on Tobacco}

Among past 30-day users, a higher level of waterpipe dependency level was found with $72 \%$ being categorized as waterpipe dependent $(n=23)$. The mean score was 15.75 (out of 33; $\mathrm{SD} \pm 6.20)$. There was a significant positive correlation $(r=0.915, p<0.001)$ between waterpipe dependence score and monthly expenditure on tobacco products (Fig. 1).

\section{Discussion}

Given the lack of data concerning the use of waterpipe tobacco smoking in Bangladesh, the present study sought to collect some baseline data from one of the most vulnerable groups (i.e., university students). Results demonstrated that $13.5 \%$ of the sample had engaged in smoking tobacco from a waterpipe and $9.4 \%$ had done so in past 30 days. The prevalence rate of having ever used waterpipes to smoke tobacco was much lower than that reported among UK university students $(38-52 \%)$ but had a similar prevalence rate for past 30-day use (8-11\%) 


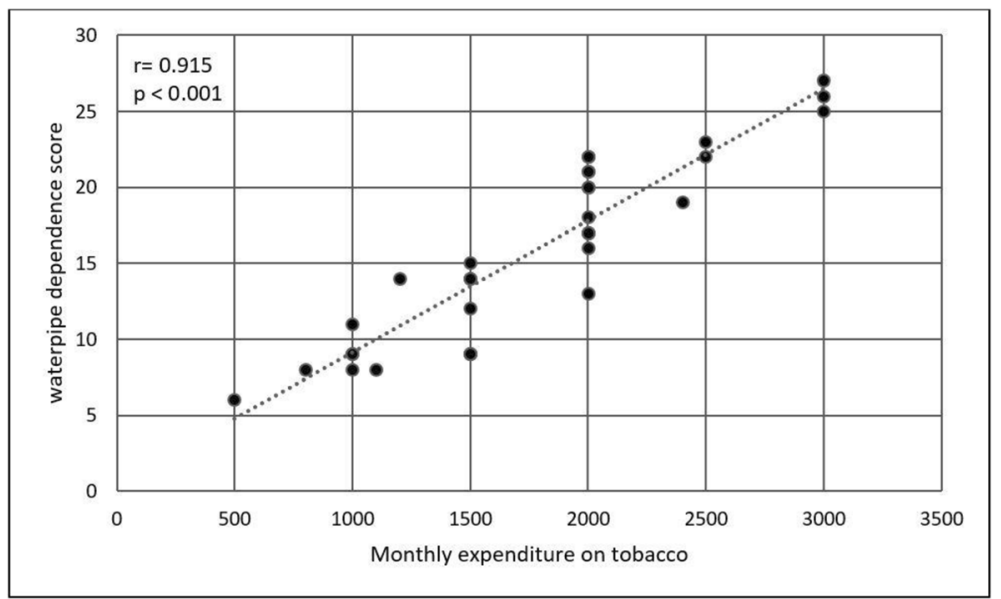

Fig. 1 Relationship between Lebanon waterpipe dependence score and monthly expenditure on tobacco

(Jackson and Aveyard 2008; Jawad et al. 2013a). Past 30-day waterpipe use in Bangladesh (9.4\%) was much lower than the past 30-day prevalence rates in Lebanon (36.9\%), West Bank (32.7\%), and Latvia (22.7\%) (Jawad et al. 2016b).

The results also found that no females in the present study reported that they had engaged in waterpipe smoking. Previous studies conducted in different Arab countries and Iran shows that male participants were more prone to addicted by waterpipe smoking (Al Ghobain et al. 2018; Danaei et al. 2017; Morton et al. 2014), and the prevalence was higher among them compared with their counterparts (Eissenberg et al. 2008; Primack et al. 2010). As tobacco consumption among the females is socially and culturally unacceptable in Bangladesh, the study result might be a reflection of his phenomenon.

Previous research indicates that smoking tobacco using a waterpipe is more harmful than cigarette smoking (Cobb et al. 2010). However, findings from the present study found that a slightly larger proportion of the sample $(27.6 \%)$ believed that waterpipe tobacco smoking was less harmful than cigarette smoking, compared with $18 \%$ who believed that that it was not. This finding are in consistent with other findings which stated that the popularity of waterpipe smoking among young adults and adolescents is because of the perception of its relative less harmful effects than cigarette smoking (Combrink et al. 2010; Jackson and Aveyard 2008). Similarly, a slightly larger proportion of the sample (30\%) believed that waterpipe tobacco smoking was less addictive than cigarette smoking compared with $25 \%$ who believed that it was not. A similar finding was found among university students in Jordan, where most of the waterpipe smoker believed that it was less harmful and less addictive than cigarette smoking (Primack et al. 2010).

Very few of the variables examined were associated with waterpipe smoking. Results demonstrated that students whose mothers were employed were more likely to using waterpipes than students whose mothers were housewives. Unsurprisingly, cigarette smokers were more likely to smoke tobacco from a waterpipe. This result is similar with a previous study conducted in Jordan shows that cigarette smokers were more prone to consume waterpipe (Primack et al. 2010). A previous study also shows that maternal occupation is closely related to the risk of tobacco consumption among Bangladeshi university students (Hassan et al. 2018). 
Results also demonstrated that $72 \%$ among those who had smoked using a waterpipe in the past 30-days were classed as being dependent using the Lebanon Waterpipe Dependence Scale. Unsurprisingly, there was a significant relationship between waterpipe dependence score and monthly expenditure on tobacco products. A previous study conducted in the UK shows that those who smoked from waterpipe daily were more dependent on waterpipe smoking (Kassim et al. 2013).

The present study is not without its limitations. Firstly, the sample (while randomly selected) was modest in size and not necessarily representative of all Bangladeshi students. Therefore, replications are required with bigger sample sizes from a wider range of Bangladeshi university students. Secondly, all the data were self-report which is subject to wellknown method biases including such things as social desirability biases and memory recall biases. The data were also cross-sectional in nature meaning that issues concerning causality could not be determined. Future studies should attempt to use other methodologies (such as qualitative interviews and focus groups, as well as longitudinal survey studies) to gain richer data than the basic kinds of information collected here using a survey. Finally, the number of variables examined was modest, and other variables should be examined in future studies to gain a more rounded overall picture of what factors contribute to waterpipe smoking and dependence upon it. Despite these limitations, the study is of existential value given that there are no prior studies ever carried out in Bangladesh previously. Therefore, the present study provides novel benchmark data for other future studies to replicate and extend.

Findings of this study could be useful for the development of (i) different health promotions program in Bangladesh to prevent students from different types of tobacco consumption, and (ii) national policymaking concerning tobacco use. Educational institutions such as universities can play a significant role in helping prevent tobacco use among students. Based on the findings here, it is recommended that each university in Bangladesh should have its own regulation and monitoring team to control tobacco use in university campus and students dormitory. University authorities should arrange different awareness campaign including workshops, incorporate such information into campus counseling programs, and promote the concept of tobacco-free campus.

Acknowledgments The authors wish to acknowledge Tazrian, Bishal, Raihan Tariq, Mukta, Trisha and Ifrad, Faculty of Nutrition and Food Science, PSTU for their voluntary support during data collection.

\section{Compliance with Ethical Standards}

Conflict of Interest The authors declare that they do not have any interests that could constitute a real, potential or apparent conflict of interest with respect to their involvement in the publication. The authors also declare that they do not have any financial or other relations (e.g. directorship, consultancy or speaker fee) with companies, trade associations, unions or groups (including civic associations and public interest groups) that may gain or lose financially from the results or conclusions in the study. Sources of funding are acknowledged.

Ethical Approval All procedures performed in this study involving human participants were in accordance with the ethical standards of University's Research Ethics Board and with the 1975 Helsinki Declaration.

Informed Consent Informed consent was obtained from all participants.

Open Access This article is licensed under a Creative Commons Attribution 4.0 International License, which permits use, sharing, adaptation, distribution and reproduction in any medium or format, as long as you give appropriate credit to the original author(s) and the source, provide a link to the Creative Commons licence, and indicate if changes were made. The images or other third party material in this article are included in the article's 
Creative Commons licence, unless indicated otherwise in a credit line to the material. If material is not included in the article's Creative Commons licence and your intended use is not permitted by statutory regulation or exceeds the permitted use, you will need to obtain permission directly from the copyright holder. To view a copy of this licence, visit http://creativecommons.org/licenses/by/4.0/.

\section{References}

Akl, E. A., Gaddam, S., Gunukula, S. K., Honeine, R., Jaoude, P. A., \& Irani, J. (2010). The effects of waterpipe tobacco smoking on health outcomes: A systematic review. International Journal of Epidemiology, 39(3), 834-857.

Al Ali, R., Rastam, S., Ibrahim, I., Bazzi, A., Fayad, S., Shihadeh, A. L., Zaatari, G. S., \& Maziak, W. (2015). A comparative study of systemic carcinogen exposure in waterpipe smokers, cigarette smokers and nonsmokers. Tobacco Control, 24(2), 125-127.

Al Ghobain, M., Ahmed, A., Abdrabalnabi, Z., Mutairi, W., \& Al Khathaami, A. (2018). Prevalence of and attitudes to waterpipe smoking among Saudi Arabian physicians. Eastern Mediterranean Health Journal, 24(3), 277-282.

Ali, M., \& Jawad, M. (2017). Health effects of waterpipe tobacco use: Getting the public health message just right. Tobacco Use Insights, 10, $1179173 \times 1769605$.

AlQahtany, F. S., Algahtani, F. H., Alshebly, M. M., Madkhaly, F. M., Ghandour, M. K., Almalki, J. H., AlOtaibi, W. S., Salim, A., \& Mendoza, F. C. (2020). Association between cigarette \& shisha smoking and the severity of polycythemia: A cross sectional study. Saudi Journal of Biological Sciences, 27(1), 460-464.

Arrazola, R. A., Singh, T., Corey, C. G., Husten, C. G., Neff, L. J., Apelberg, B. J., Bunnell, R. E., Choiniere, C. J., King, B. A., \& Cox, S. (2015). Tobacco use among middle and high school students-United States, 2011-2014. MMWR. Morbidity and Mortality Weekly Report, 64(14), 381.

Babar, N. F., \& Riaz, S. (2015). Prevalence and factors associated with sheesha smoking in a sample of medical students. Journal of Postgraduate Medical Institute (Peshawar-Pakistan), 29(3).

Baer, J. S., Stacy, A., \& Larimer, M. (1991). Biases in the perception of drinking norms among college students. Journal of Studies on Alcohol, 52(6), 580-586.

Baheiraei, A., Sighaldeh, S. S., Ebadi, A., Kelishadi, R., \& Majdzadeh, S. R. (2015). Psycho-social needs impact on hookah smoking initiation among women: A qualitative study from Iran. International Journal of Preventive Medicine, 6, 79.

Borsari, B., \& Carey, K. B. (2003). Descriptive and injunctive norms in college drinking: A meta-analytic integration. Journal of Studies on Alcohol, 64(3), 331-341.

Boskabady, M. H., Farhang, L., Mahmodinia, M., Boskabady, M., \& Heydari, G. R. (2012). Comparison of pulmonary function and respiratory symptoms in water pipe and cigarette smokers. Respirology, 17(6), 950956.

Cobb, C. O., Shihadeh, A., Weaver, M. F., \& Eissenberg, T. (2010). Waterpipe tobacco smoking and cigarette smoking: A direct comparison of toxicant exposure and subjective effects. Nicotine \& Tobacco Research, 13(2), 78-87.

Combrink, A., Irwin, N., Laudin, G., Naidoo, K., Plagerson, S., \& Mathee, A. (2010). High prevalence of hookah smoking among secondary school students in a disadvantaged community in Johannesburg. South African Medical Journal, 100(5), 297-299.

Danaei, M., Jabbarinejad-Kermani, A., Mohebbi, E., \& Momeni, M. (2017). Waterpipe tobacco smoking prevalence and associated factors in the southeast of Iran. Addiction \& Health, 9(2), 72-80.

Dean, A., Sullivan, K., \& Soe, M. (2014). OpenEpi: Open source epidemiologic statistics for public health, version 2.3.1. Retrieved December 7, 2019, from: https://www.neuroaro.gov.ng/main/index. $\mathrm{php} /$ resources/article-blog/210-the-sample-size-determination-gibberish-and-way-out

Eissenberg, T., Ward, K. D., Smith-Simone, S., \& Maziak, W. (2008). Waterpipe tobacco smoking on a US College campus: Prevalence and correlates. Journal of Adolescent Health, 42(5), 526-529.

Hammal, F., Mock, J., Ward, K., Eissenberg, T., \& Maziak, W. (2008). A pleasure among friends: How narghile (waterpipe) smoking differs from cigarette smoking in Syria. Tobacco Control, 17(2), e3.

Hassan, M. S., Hossain, M. K., \& Khan, H. T. (2018). Prevalence and predictors of tobacco smoking among university students in Sylhet Division, Bangladesh. International Health, 11, 306-313.

Hauser, C. D., Mailig, R., Stadtler, H., Reed, J., Chen, S., Uffman, E., \& Bernd, K. (2020). Waterpipe tobacco smoke toxicity: The impact of waterpipe size. Tobacco Control, $29($ Suppl 2), s90-s94.

Helen, G. S., Benowitz, N. L., Dains, K. M., Havel, C., Peng, M., \& Jacob, P. (2014). Nicotine and carcinogen exposure after water pipe smoking in hookah bars. Cancer Epidemiology and Prevention Biomarkers, 23(6), 1055-1066. 
Jackson, D., \& Aveyard, P. (2008). Waterpipe smoking in students: Prevalence, risk factors, symptoms of addiction, and smoke intake. Evidence from one British university. BMC Public Health, 8(1), 174.

Jacob, P., Raddaha, A. H. A., Dempsey, D., Havel, C., Peng, M., Yu, L., \& Benowitz, N. L. (2013). Comparison of nicotine and carcinogen exposure with water pipe and cigarette smoking. Cancer Epidemiology and Prevention Biomarkers, 22(5), 765-772.

Jawad, M., Abass, J., Hariri, A., Rajasooriar, K., Salmasi, H., Millett, C., \& Hamilton, F. (2013a). Waterpipe smoking: Prevalence and attitudes among medical students in London. International Journal of Tuberculosis and Lung Disease, 17(1), 137-140.

Jawad, M., McEwen, A., McNeill, A., \& Shahab, L. (2013b). To what extent should waterpipe tobacco smoking become a public health priority? Addiction, 108(11), 1873-1884.

Jawad, M., Choaie, E., Brose, L., Dogar, O., Grant, A., Jenkinson, E., McEwen, A., Millett, C., \& Shahab, L. (2016a). Waterpipe tobacco use in the United Kingdom: A cross-sectional study among university students and stop smoking practitioners. PLoS One, 11(1), e0146799.

Jawad, M., Lee, J. T., \& Millett, C. (2016b). Waterpipe tobacco smoking prevalence and correlates in 25 Eastern Mediterranean and Eastern European countries: Cross-sectional analysis of the Global Youth Tobacco Survey. Nicotine \& Tobacco Research, 18(4), 395-402.

Kassem, N. O. F., Kassem, N. O., Liles, S., Reilly, E., Kas-Petrus, F., Posis, A. I. B., \& Hovell, M. F. (2020). Waterpipe device cleaning practices and disposal of waste associated with waterpipe tobacco smoking in homes in the USA. Tobacco Control, 29(Suppl 2), s123-s130.

Kassim, S., Al-Bakri, A., \& al'Absi, M., \& Croucher, R. (2013). Waterpipe tobacco dependence in UK male adult residents: A cross-sectional study. Nicotine \& Tobacco Research, 16(3), 316-325.

Knishkowy, B., \& Amitai, Y. (2005). Water-pipe (narghile) smoking: An emerging health risk behavior. Pediatrics, 116(1), e113-e119.

Larimer, M. E., \& Neighbors, C. (2003). Normative misperception and the impact of descriptive and injunctive norms on college student gambling. Psychology of Addictive Behaviors, 17(3), 235-243.

Leavens, E. L., Brett, E. I., Morgan, T. L., Lopez, S. V., Shaikh, R. A., Leffingwell, T. R., \& Wagener, T. L. (2018). Descriptive and injunctive norms of waterpipe smoking among college students. Addictive Behaviors, 77, 59-62.

Lee, J. J., Wu, Y., Wang, M. P., Yeung, K. C.-Y., Wong, J. Y.-H., \& Smith, R. (2020). Waterpipe smoking among university students in Hong Kong: A cross-sectional study. BMC Public Health, 20, 1-10.

Lipkus, I. M., Reboussin, B. A., Wolfson, M., \& Sutfin, E. L. (2014). Assessing and predicting susceptibility to waterpipe tobacco use among college students. Nicotine \& Tobacco Research, 17(9), 1120-1125.

Maziak, W., Eissenberg, T., Rastam, S., Hammal, F., Asfar, T., Bachir, M. E., Fouad, M. F., \& Ward, K. D. (2004). Beliefs and attitudes related to narghile (waterpipe) smoking among university students in Syria. Annals of Epidemiology, 14(9), 646-654.

Maziak, W., Taleb, Z. B., Bahelah, R., Islam, F., Jaber, R., Auf, R., \& Salloum, R. G. (2015). The global epidemiology of waterpipe smoking. Tobacco Control, 24(Suppl 1), i3-i12.

Morton, J., Song, Y., Fouad, H., El Awa, F., El Naga, R. A., Zhao, L., Palipudi, K., \& Asma, S. (2014). Crosscountry comparison of waterpipe use: Nationally representative data from 13 low and middle-income countries from the Global Adult Tobacco Survey (GATS). Tobacco Control, 23(5), 419-427.

Neighbors, C., Lee, C. M., Lewis, M. A., Fossos, N., \& Larimer, M. E. (2007). Are social norms the best predictor of outcomes among heavy-drinking college students? Journal of Studies on Alcohol and Drugs, $68(4), 556-565$.

Nguyen, T., Hlangothi, D., Martinez III, R. A., Jacob, D., Anthony, K., Nance, H., \& Saleh, M. A. (2013). Charcoal burning as a source of polyaromatic hydrocarbons in waterpipe smoking. Journal of Environmental Science and Health, Part B, 48(12), 1097-1102.

Perkins, H. W. (2002). Social norms and the prevention of alcohol misuse in collegiate contexts. Journal of Studies on Alcohol (Supplement, 14), 164-172.

Primack, B. A., Sidani, J., Agarwal, A. A., Shadel, W. G., Donny, E. C., \& Eissenberg, T. E. (2008). Prevalence of and associations with waterpipe tobacco smoking among US university students. Annals of Behavioral Medicine, 36(1), 81-86.

Primack, B. A., Fertman, C. I., Rice, K. R., Adachi-Mejia, A. M., \& Fine, M. J. (2010). Waterpipe and cigarette smoking among college athletes in the United States. Journal of Adolescent Health, 46(1), 45-51.

Qasim, H., Alarabi, A. B., Alzoubi, K. H., Karim, Z. A., Alshbool, F. Z., \& Khasawneh, F. T. (2019). The effects of hookah/waterpipe smoking on general health and the cardiovascular system. Environmental health \& preventive medicine, 24(1), 1-17.

Raad, D., Gaddam, S., Schunemann, H. J., Irani, J., Jaoude, P. A., Honeine, R., \& Akl, E. A. (2011). Effects of water-pipe smoking on lung function: A systematic review and meta-analysis. Chest, 139(4), 764-774. 
Radwan, G., Hecht, S. S., Carmella, S. G., \& Loffredo, C. A. (2012). Tobacco-specific nitrosamine exposures in smokers and nonsmokers exposed to cigarette or waterpipe tobacco smoke. Nicotine \& Tobacco Research, 15(1), 130-138.

Ross, L., Greene, D., \& House, P. (1977). The "false consensus effect": An egocentric bias in social perception and attribution processes. Journal of Experimental Social Psychology, 13(3), 279-301.

Salameh, P., Waked, M., \& Aoun, Z. (2008). Waterpipe smoking: Construction and validation of the Lebanon Waterpipe Dependence Scale (LWDS-11). Nicotine \& Tobacco Research, 10(1), 149-158.

Salloum, R. G., Lee, J., Mostafa, A., Abu-Rmeileh, N. M., Hamadeh, R. R., Darawad, M. W., et al. (2019). Waterpipe tobacco smoking among university students in three eastern Mediterranean countries: Patterns, place, and price. Substance Use \& Misuse, 54(14), 2275-2283.

Selim, G. M., Fouad, H., \& Ezzat, S. (2013). Impact of shisha smoking on the extent of coronary artery disease in patients referred for coronary angiography. Anadolu Kardiyoloji Dergisi, 13(7), 647-654I.

Sepetdjian, E., Saliba, N., \& Shihadeh, A. (2010). Carcinogenic PAH in waterpipe charcoal products. Food and Chemical Toxicology, 48(11), 3242-3245.

Sibai, A. M., Tohme, R. A., Almedawar, M. M., Itani, T., Yassine, S. I., Nohra, E. A., \& Isma'eel, H. A. (2014). Lifetime cumulative exposure to waterpipe smoking is associated with coronary artery disease. Atherosclerosis, 234(2), 454-460.

Sidani, J. E., Shensa, A., Yabes, J., Fertman, C., \& Primack, B. A. (2019). Waterpipe tobacco use in college and non-college young adults in the USA. Family Practice, 36(2), 103-109.

Smith-Simone, S., Maziak, W., Ward, K. D., \& Eissenberg, T. (2008). Waterpipe tobacco smoking: Knowledge, attitudes, beliefs, and behavior in two US samples. Nicotine \& Tobacco Research, 10(2), 393-398.

Tamim, H., Terro, A., Kassem, H., Ghazi, A., Khamis, T. A., Hay, M. M. A., \& Musharrafieh, U. (2003). Tobacco use by university students, Lebanon, 2001. Addiction, 98(7), 933-939.

WHO. (2015). Advisory note: Waterpipe tobacco smoking: Health effects, research needs and recommended actions for regulators. Geneva, Switzerland: World Health Organization.

Publisher's Note Springer Nature remains neutral with regard to jurisdictional claims in published maps and institutional affiliations.

\title{
Affiliations
}

\section{Md. Sabbir Ahmed ${ }^{1} \cdot$ Liton Chandra Sen ${ }^{1} \cdot$ Safayet Khan $^{2} \cdot$ Fakir Md Yunus $^{3} \cdot$ Mark D. $^{\circ}$ Griffiths $^{4}$}

\author{
Md. Sabbir Ahmed \\ sabbir.nfs@gmail.com \\ Liton Chandra Sen \\ liton.sen@pstu.ac.bd \\ Safayet Khan \\ safayet.khan@bracu.ac.bd \\ Fakir Md Yunus \\ fakir.yunus@usask.ca
}

1 Department of Community Health and Hygiene, Faculty of Nutrition and Food Science, Patuakhali Science and Technology University, Patuakhali, 8602 Dhaka, Bangladesh

2 BRAC Institute of Educational Development, BRAC University, House 113/A, Road 2, Niketan, Gulshan 1, Dhaka 1212, Bangladesh

3 College of Pharmacy and Nutrition, The University of Saskatchewan, 104 Clinic Place, Saskatoon, SK S7N 2Z4, Canada

4 Psychology Department, Nottingham Trent University, 50 Shakespeare Street, Nottingham NG1 4FQ, UK 